\title{
Factors Associated with Delayed Initiation and Cessation of Breastfeeding Among Working Mothers in Abu Dhabi, the United Arab Emirates
}

\author{
Zainab Taha (D) \\ Ahmed Ali Hassan ${ }^{2}$ \\ Ludmilla Wikkeling-Scott ${ }^{\prime}$ \\ Dimitrios Papandreou' \\ 'Department of Health Sciences, College \\ of Natural and Health Sciences, Zayed \\ University, Abu Dhabi, U.A.E; \\ ${ }^{2}$ Department of Research, Taami for \\ Agricultural and Animal Production, \\ Khartoum, Sudan
}

Introduction: Despite the enormous benefits of breastfeeding, working mothers face more challenges to meet the World Health Organization (WHO) recommendations regarding successful breastfeeding practices. Little research has been done to understand the breastfeeding practices among working mothers in the United Arab Emirates (UAE). Thus, the aim of this study was to investigate the prevalence and factors associated with delayed initiation and cessation of breastfeeding among working mothers with children under the age of two years in Abu Dhabi, the UAE. Methods: A cross-sectional multicenter study was conducted from March to September 2017. The study included both Emirati and non-Emirati mothers of children below the age of two years. The data were collected from seven government health care centers in Abu Dhabi as well as from the community. Mothers with young children attending the centers during the study days were approached by trained research assistants, who provided oral and written information about the study.

Results: Among the 1610 mother-child pairs with complete data who were included in this study, 606 were working mothers giving an employment rate of $37.6 \%$. The mean (standard deviation) of maternal age and children's age were 30.9 (5.1) years and 8.6 (6.1) months, respectively. Of the 606 mothers, 217 (35.8\%) delayed initiation of breastfeeding, and 359 (59.2\%) ceased breastfeeding. In multivariable logistic regression analysis, factors associated with delayed breastfeeding initiation among working mothers were older mother age (adjusted odds ratio [AOR] 1.04, 95\% confidence interval $[\mathrm{CI}] 1.01,1.08$ ), being of non-Arab nationality (AOR 2.24, 95\% CI 1.53, 3.27), caesarean section (AOR 2.70, 95\% CI 1.84, 3.96), non-rooming-in (AOR 3.85, 95\% CI 1.56, 9.51) and mothers with low birth weight children (AOR 2.47, 95\% CI 1.23, 4.94). The main factors associated with cessation of breastfeeding were being of non-Arab nationality (AOR 1.59, 95\% CI 1.09, 2.31) and mother with high-income rating (AOR 2.79, 95\% CI 1.36, 5.75).

Conclusion: The study highlighted the need for urgent actions to improve the working mothers' conditions in order to promote optimal breastfeeding practices, including both early initiation and continuation of breastfeeding among all mothers in the UAE regardless of employment status. Policies to improve EBF rates among professional working mothers should include maternity leave extension to enable mothers to continue breastfeeding.

Keywords: working mother, initiation of breastfeeding, cessation of breastfeeding, caesarean section, rooming-in, low birth weight, United Arab Emirates

\section{Introduction}

The World Health Organization (WHO) and the United Nations Children's Fund (UNICEF) recommend early initiation of breastfeeding within one hour of birth, ${ }^{1}$ exclusive breastfeeding (EBF) for the first six months of life, ${ }^{2}$ and introduction of
Correspondence: Zainab Taha

Tel +97l-2-5993 III

Email Zainab.taha@zu.ac.ae 
complementary foods at six months together with continued breastfeeding up to two years of age or beyond. ${ }^{3}$

The importance of early breastfeeding initiation has been well documented as one of the main steps for promoting exclusive breastfeeding for six months of life as well as the overall duration of breastfeeding. ${ }^{4}$ Provision of breast milk to infants within one hour of birth is referred to as "early initiation of breastfeeding," and it ensures that the infant receives the colostrum, or "first milk", which is rich in protective factors. ${ }^{5}$

Exclusive breastfeeding up to six months is part of the optimal breastfeeding. The benefits of EBF for the first six months have been well documented in providing infants with optimal nutrition, growth, and development. ${ }^{3}$

Continuing breastfeeding for prolonged durations beyond six months also contributes to infants and young children's health and well-being as it has been found to be associated with several optimal infants and maternal health outcomes. ${ }^{6}$ It was shown to provide a continuous essential source of energy and nutrients for children aged 6-23 months. Studies have shown that breastfeeding reduces the onset of childhood diseases and may protect infants and young children from diarrhea and respiratory infections, as well as malnutrition, ${ }^{7}$ while the immunological component of breast milk provides infants with a strong immune system. $^{8}$

The UAE health authorities have consistently made efforts to promote breastfeeding and encourage mothers to breastfeed their babies. Nationwide efforts have been initiated and implemented in hospitals, health centers, and the community. ${ }^{9}$ At each level of these health care systems, several breastfeeding policies and guidelines have been developed to promote breastfeeding and increase the exclusive breastfeeding rate.

However, the recommendation of breastfeeding could be challenging for employed mothers. ${ }^{10,11}$ Several studies in different parts of the world reported low rates of exclusive breastfeeding among working mothers. ${ }^{12-14}$ Mother's return to work often negatively affects the consistency of breastfeeding practices. The rate of EBF is higher among mothers who are not employed compared to those employed. ${ }^{15}$ Studies showed that maternity leave is positively associated with the duration of breastfeeding. ${ }^{16,17}$

Since early initiation of breastfeeding has been recommended to promote successful breastfeeding, it would be imperative to assess this important practice among working mothers. Another study found that women employed full time were less likely to initiate breastfeeding compared to mothers who were unemployed/students, after adjustment for confounding factors [adjusted rate ratio $(\mathrm{aRR})=0.92 ; 95 \%$ confidence interval (CI) 0.89, 0.96]. ${ }^{18}$ Moreover, evidence from an additional study found that among employed mothers, those who returned to work within four months postpartum were less likely to start breastfeeding compared to women who returned at 5 or 6 months $[\mathrm{aRR}=0.95$; $95 \%$ CI $0.92,0.99$ ]. ${ }^{18}$ Additionally, women who returned within the first six weeks were much less likely to start breastfeeding $[\mathrm{aRR}=0.85 ; 95 \%$ CI $0.77,0.94]$. Additionally, data from a study in the United States that included 817 women aged 18 and older, using logistic regression, revealed that the odds of breastfeeding initiation were higher for women who held professional jobs, were primiparae, had a graduate degree, did not smoke prenatally, had no breastfeeding problems, and had family or friends who breastfed. ${ }^{19}$ Finally, a study in Ethiopia revealed the requirement of women to return to paid employment was the main reason for the discontinuation of EBF. ${ }^{20}$

The UAE has been ranked one of the mostdeveloped countries globally with sustainable growth in many fields, including economy, trade, investment and communications, infrastructure, and human and social development. Women play an important role in this progress. The female labor force participation rate in the UAE development has shown a remarkable increase from 1990 to 2019 with a rate of $28.09 \%$ and $52.39 \%$, respectively. ${ }^{21}$ Therefore, maternal employment rates in the UAE have increased rapidly in recent years, and little is known about how this influences women's breastfeeding initiation.

Regardless of the health providers' extensive efforts in the UAE to promote breastfeeding practices, the country is still experiencing a breastfeeding rate below the target recommended by the WHO, which is $50 \%{ }^{22}$ Studies have identified several barriers to optimal breastfeeding practices in the UAE. They include insufficient milk production and breastfeeding problems eg, nipple problem, mother's age, education, delivery mode, and nonrooming. $^{23}$

The aim of this study was to investigate the prevalence and factors associated with delayed initiation and cessation of breastfeeding among working mothers with children under the age of two years in Abu Dhabi, the UAE. 


\section{Materials and Methods}

\section{Participants and Data Collection}

The current study data were extracted from a crosssectional study, where 1822 mothers of children below the age of two years were recruited from the community and health care centers located in different geographical areas in Abu Dhabi from March to September 2017. The study sample included Emirati and non-Emirati families. Seven governmental clinics that render maternal and child health services were approved for data collection. Mothers with young children attending the centers during the study were approached by trained female research assistants, who provided oral and written information about the study. Mothers, who met the inclusion criteria of having at least one child under two years of age, were interviewed by the research assistants using a structured questionnaire. A detailed description of the study design and sampling has been published elsewhere. ${ }^{24}$ The study was approved by the research ethics committee of Zayed University (ZU17_006_F) and complied with the Declaration of Helsinki Ethical Principles for Medical Research. Additional ethical clearance was also obtained from the Abu Dhabi Health Services Company.

\section{Study Instrument}

The study instrument was a questionnaire that has been validated by conducting a pilot study utilizing face validity before distributing the questions. Participants were divided into two categories, namely early initiation, and delayed initiation. To describe the results, these two groups were compared based on factors that include: family demographics (eg, parent education, age, nationality), child's information (eg, child gender, birth weight, delivery mode, childbirth order), and infant feeding practices (eg, initiation of breastfeeding, cessation of breastfeeding and received breastfeeding advice during pregnancy). The questionnaire was designed in English and Arabic, using a cross-translation strategy, where a local Arabic speaker translated the English document into Arabic. The same procedure was repeated where another local Arabic speaker translated the questionnaire back to English without accessing the original translation. The final version of the instrument was prepared considering the errors that have been recognized and identified through the translation. More information about the study methodology was described in the previous study. ${ }^{24}$

\section{Study Inclusion and Exclusion Criteria}

This study included only working mothers who have less than 24 months babies from the data collected. All working mothers (governmental or non-governmental) with children under two years of age, who have completed data regarding sociodemographic factors (eg, age, education), pregnancy and factors related to the mode of delivery, and breastfeeding practices (eg, breastfeeding initiation and cessation) were included in this study.

\section{Statistical Analysis}

Data were analyzed by using Statistical Package for the Social Science (IBM SPSS Statistics for Windows, Version 20.0. Armonk, NY: IBM Corp.). Both descriptive and inferential statistics were used to describe the results. $T$-test and Chi-square tests were applied to analyze continuous and categorical data, respectively. Variables with significant $\mathrm{p}$-values $(<0.05)$ in univariate analysis were further analyzed using multivariable logistic analysis with the breastfeeding initiation as a dependent variable, ie early initiation of breastfeeding was coded as (0) and delayed as (1). Another dependent variable (cessation of breastfeeding), not the cessation of breastfeeding, was coded (0) and cessation of breastfeeding (1). If one of the cells contained zero in the univariate, eg, exclusive breastfeeding, it was not included in the logistic regression. The independent variables included: sociodemographic variables, such as maternal age, nationality, parent education, pre-pregnancy body mass index (BMI); pregnancy variables such as gestational age at delivery and receiving of breastfeeding advice during pregnancy; delivery variables such as mode of delivery (vaginal/caesarean birth), child variables such as gender, birth weight, and birth order; breastfeeding variables such as receiving of breastfeeding advice during pregnancy, rooming-in. Odds Ratio (OR) and 95\% Confidence Interval (CI) were calculated. P-value $<0.05$ was considered to be significant.

\section{Operational Definitions}

Operational definitions are shown in Table 1.

\section{Results}

From the original sample $(\mathrm{N}=1822)$, a total of 1610 mother-child pairs who had completed data that are required for the analysis of the current study were identified. Among the 1610 participants, 606 were working mothers giving an employment rate of $37.6 \%$. 
Table I Operational Definitions

\begin{tabular}{|c|c|}
\hline Variables & Operational Definitions \\
\hline Maternal age & Maternal age in years at the time of interview \\
\hline Maternal education & Maternal higher level of education categorized $<$ Secondary level and $\geq$ Secondary level \\
\hline Father education & Maternal higher level of education categorized $<$ Secondary level and $\geq$ Secondary level \\
\hline Nationality & $\begin{array}{l}\text { Arab nationality: included all Emirati mothers and other Arab. } \\
\text { Non-Arab nationality: included Asian mothers and other nationalities. }\end{array}$ \\
\hline Marital status & Married and unmarried \\
\hline Pre-pregnancy BMI & $\begin{array}{l}\text { The weight in kilograms divided by the square of the height in metres }(\mathrm{kg} / \mathrm{m} 2)(1) \text {. Based on the index, it was } \\
\text { subcategorized to normal between } 18.50 \text { and } 24.99 \text {, and abnormal (underweight }<18.5 \text {, overweight } 25-29.9 \\
\text { and obese } \geq 30 \text { ) }\end{array}$ \\
\hline Income rating & The mother rating the family's overall financial well-being as excellent, very good, good, fair, and poor \\
\hline $\begin{array}{l}\text { Received breastfeeding advice } \\
\text { during pregnancy }\end{array}$ & Any received information, positive or negative things, about breastfeeding before or after delivery. \\
\hline Mode of delivery & Vaginal or caesarian \\
\hline Child gender & Male or female \\
\hline Child order & Ist child order and $\geq 2$ \\
\hline Rooming-in & $\begin{array}{l}\text { Mother and infant being placed in the same room immediately after leaving the delivery suite, and, in the case } \\
\text { of CS, when the mother was able to respond to her infant. } \\
\text { Not rooming-in: babies who were not in the same room with mother since the delivery time, or those who } \\
\text { required separation out of rooming-in in the middle of the course due to poor condition of babies or due to } \\
\text { maternal condition. }\end{array}$ \\
\hline Exclusive breastfeeding & $\begin{array}{l}\text { The infant being fed only breast milk without any other oral intake, except medications and vitamins, for the } \\
\text { first six months of life. }\end{array}$ \\
\hline Cessation of breastfeeding & $\begin{array}{l}\text { The mother was asked during the interview direct question if the index child "is breastfeeding", yes or no } \\
\text { was indication for stopping exclusive breastfeeding for children below } 6 \text { months and continued breastfeeding } \\
\text { for others. }\end{array}$ \\
\hline Initiation of breastfeeding & $\begin{array}{l}\text { Early initiation of breastfeeding: Provision of mother's breast milk to infants within one hour of birth. } \\
\text { Delayed initiation of breastfeeding: when the infant initiated breastfeeding within more than one hour after } \\
\text { birth. }\end{array}$ \\
\hline Gestational age at delivery & $\begin{array}{l}\text { The duration of pregnancy in weeks, any baby delivered before } 37 \text { weeks of pregnancy was considered as } \\
\text { preterm and } \geq 37 \text { weeks as full-term baby. }\end{array}$ \\
\hline Childbirth weight at delivery & $\begin{array}{l}\text { The baby weight in grams immediately after delivery, any baby delivered with weight }<2500 \text { grams was } \\
\text { considered as LBW; and } \geq 2500 \text { grams as normal weight. }\end{array}$ \\
\hline
\end{tabular}

Frequency analysis showed that among the 606 working mothers, there were 217 (35.8\%) who reportedly had delayed initiation of breastfeeding within more than one hour after birth and 359 (59.2\%) who had already stopped exclusive or any breastfeeding. All mothers who were exclusively breastfeeding their children at the interview time 83 (13.9\%) maintained breastfeeding (Table 2).
In multivariable logistic regression analysis, factors associated with delayed initiation of breastfeeding among working mothers were older mother age (Adjusted Odds Ratio [AOR] 1.04, 95\% CI 1.01, 1.08), being non-Arab nationality (AOR 2.24, 95\% CI 1.53, 3.27), caesarean section (AOR 2.70, 95\% CI 1.84, 3.96), non-rooming-in (AOR 3.85, 95\% CI 1.56, 9.51) and mothers with low birth weight children (AOR 2.47, 95\% CI 1.23, 4.94) (Table 3). 
Table 2 Sociodemographic Characteristics of the Studied Participants in Abu Dhabi, the United Arab Emirates (N=606)

\begin{tabular}{|c|c|c|c|c|c|c|c|c|}
\hline \multirow{3}{*}{\multicolumn{2}{|c|}{ Variables }} & \multirow{3}{*}{$\begin{array}{c}\begin{array}{c}\text { Total } \\
(\mathrm{N}=606)\end{array} \\
\text { Mean } \\
\text { (SD) }\end{array}$} & \multicolumn{3}{|c|}{ Initiation of Breastfeeding } & \multicolumn{3}{|c|}{ Cessation of Breastfeeding } \\
\hline & & & \multirow{2}{*}{$\begin{array}{c}\begin{array}{c}\text { Early } \\
(\mathrm{n}=389)\end{array} \\
\begin{array}{c}\text { Mean } \\
(\mathrm{SD})\end{array}\end{array}$} & \multirow{2}{*}{$\begin{array}{c}\begin{array}{c}\text { Delayed } \\
(\mathrm{n}=217)\end{array} \\
\begin{array}{c}\text { Mean } \\
(\mathrm{SD})\end{array}\end{array}$} & \multirow[t]{2}{*}{ P-value } & \multirow{2}{*}{$\begin{array}{c}\begin{array}{c}\text { Yes } \\
(n=247)\end{array} \\
\begin{array}{c}\text { Mean } \\
(S D)\end{array}\end{array}$} & \multirow{2}{*}{\begin{tabular}{|c|} 
No \\
$(n=359)$
\end{tabular}} & \multirow[t]{2}{*}{ P-value } \\
\hline & & & & & & & & \\
\hline Maternal age, years & & $30.9(5.1)$ & $30.4(5.4)$ & $31.8(4.5)$ & 0.001 & $30.9(5.5)$ & $30.9(4.8)$ & 0.993 \\
\hline Maternal education & $\begin{array}{l}<\text { Secondary level } \\
\geq \text { Secondary level }\end{array}$ & $\begin{array}{c}24(4.0) \\
582(96.0)\end{array}$ & $\begin{array}{c}20(5.1) \\
369(94.9)\end{array}$ & $\begin{array}{c}4(1.8) \\
213(98.2)\end{array}$ & 0.051 & $\begin{array}{c}15(6.1) \\
232(93.9)\end{array}$ & $\begin{array}{c}9(2.5) \\
350(97.5)\end{array}$ & 0.027 \\
\hline Paternal education & $\begin{array}{l}<\text { Secondary level } \\
\geq \text { Secondary level }\end{array}$ & $\begin{array}{c}16(2.6) \\
590(97.4)\end{array}$ & $\begin{array}{c}14(3.6) \\
375(96.4)\end{array}$ & $\begin{array}{c}2(0.9) \\
215(99.1)\end{array}$ & 0.063 & $\begin{array}{c}\text { II (4.5) } \\
236(95.5)\end{array}$ & $\begin{array}{c}5(1.4) \\
354(98.6)\end{array}$ & 0.021 \\
\hline Nationality & $\begin{array}{l}\text { Arab } \\
\text { Non-Arab }\end{array}$ & $\begin{array}{l}418(69.0) \\
188(31.0)\end{array}$ & $\begin{array}{l}295(75.8) \\
94(24.2)\end{array}$ & $\begin{array}{l}123(56.7) \\
94(43.3)\end{array}$ & $<0.001$ & $\begin{array}{l}187(75.7) \\
60(24.3)\end{array}$ & $\begin{array}{l}231(64.3) \\
128(35.7)\end{array}$ & 0.003 \\
\hline Marital status & $\begin{array}{l}\text { Married } \\
\text { Unmarried }\end{array}$ & $\begin{array}{c}588(97.0) \\
18(3.0)\end{array}$ & $\begin{array}{c}378(97.2) \\
I I(2.8)\end{array}$ & $\begin{array}{c}210(96.8) \\
7(3.2)\end{array}$ & 0.782 & $\begin{array}{c}237(96.0) \\
10(4)\end{array}$ & $\begin{array}{c}351(97.8) \\
8(2.2)\end{array}$ & 0.195 \\
\hline Pre-pregnancy BMI & $\begin{array}{l}\text { Normal BMI } \\
\text { Abnormal BMI }\end{array}$ & $\begin{array}{l}389(64.2) \\
217(35.8)\end{array}$ & $\begin{array}{l}246(63.2) \\
143(36.8)\end{array}$ & $\begin{array}{l}143(65.9) \\
74(34.1)\end{array}$ & 0.513 & $\begin{array}{l}145() 58.7 \\
102(4 \mid .3)\end{array}$ & $\begin{array}{l}244(68.0) \\
115(32.0)\end{array}$ & 0.019 \\
\hline Income rating & $\begin{array}{l}<\text { good } \\
\geq \text { good }\end{array}$ & $\begin{array}{c}34(5.6) \\
572(94.4)\end{array}$ & $\begin{array}{c}24(6.2) \\
365(93.8)\end{array}$ & $\begin{array}{c}10(4.6) \\
207(95.4)\end{array}$ & 0.423 & $\begin{array}{c}21(8.5) \\
226(9 I .5)\end{array}$ & $\begin{array}{c}13(3.6) \\
346(96.4)\end{array}$ & 0.010 \\
\hline $\begin{array}{l}\text { Received breastfeeding } \\
\text { advice during pregnancy }\end{array}$ & $\begin{array}{l}\text { Yes } \\
\text { No }\end{array}$ & $\begin{array}{l}537(88.6) \\
69(11.4)\end{array}$ & $\begin{array}{c}339(87.1) \\
50(12.9)\end{array}$ & $\begin{array}{l}198(91.2) \\
19(8.8)\end{array}$ & 0.128 & $\begin{array}{l}217(87.9) \\
30(12.1)\end{array}$ & $\begin{array}{l}320(89.1) \\
39(10.9)\end{array}$ & 0.625 \\
\hline Mode of delivery & $\begin{array}{l}\text { Vaginal } \\
\text { Caesarean }\end{array}$ & $\begin{array}{l}430(71.0) \\
176(29.0)\end{array}$ & $\begin{array}{l}312(80.2) \\
77(19.8)\end{array}$ & $\begin{array}{l}118(54.4) \\
99(45.6)\end{array}$ & $<0.001$ & $\begin{array}{l}178(72.1) \\
69(27.9)\end{array}$ & $\begin{array}{l}252(70.2) \\
107(29.8)\end{array}$ & 0.618 \\
\hline Child gender & $\begin{array}{l}\text { Male } \\
\text { Female }\end{array}$ & $\begin{array}{l}297(49.0) \\
309(51.0)\end{array}$ & $\begin{array}{l}187(48.1) \\
202(51.9)\end{array}$ & $\begin{array}{l}110(50.7) \\
107(49.3)\end{array}$ & 0.536 & $\begin{array}{l}130(52.6) \\
117(47.4)\end{array}$ & $\begin{array}{l}167(46.5) \\
192(53.5)\end{array}$ & 0.139 \\
\hline Child order & $\begin{array}{l}\text { I }^{\text {st }} \text { child order } \\
\geq 2\end{array}$ & $\begin{array}{l}206(34.0) \\
400(66.0)\end{array}$ & $\begin{array}{l}266(68.4) \\
123(31.6)\end{array}$ & $\begin{array}{l}134(61.8) \\
83(38.2)\end{array}$ & 0.099 & $\begin{array}{l}75(30.4) \\
172(69.6)\end{array}$ & $\begin{array}{l}|3|(36.5) \\
228(63.5)\end{array}$ & 0.118 \\
\hline Rooming-in & $\begin{array}{l}\text { Yes } \\
\text { No }\end{array}$ & $\begin{array}{c}578(95.4) \\
28(4.6)\end{array}$ & $\begin{array}{c}381(97.9) \\
8(2.1)\end{array}$ & $\begin{array}{c}197(90.8) \\
20(9.2)\end{array}$ & $<0.001$ & $\begin{array}{c}233(94.3) \\
14(5.7)\end{array}$ & $\begin{array}{c}345(96.1) \\
14(3.9)\end{array}$ & 0.308 \\
\hline Exclusive breastfeeding* & $\begin{array}{l}\text { Yes } \\
\text { No }\end{array}$ & $\begin{array}{c}83(13.9) \\
516(86.1)\end{array}$ & $\begin{array}{c}49(12.8) \\
334(87.2)\end{array}$ & $\begin{array}{c}34(15.7) \\
182(84.3)\end{array}$ & 0.315 & $\begin{array}{c}0(0.0) \\
242(100)\end{array}$ & $\begin{array}{c}83(23.2) \\
274(76.8)\end{array}$ & $<0.001$ \\
\hline Cessation of breastfeeding & $\begin{array}{l}\text { Yes } \\
\text { No }\end{array}$ & $\begin{array}{l}247(40.8) \\
359(59.2)\end{array}$ & $\begin{array}{l}166(42.7) \\
223(57.3)\end{array}$ & $\begin{array}{l}81(37.3) \\
136(62.7)\end{array}$ & 0.199 & - & - & - \\
\hline Initiation of breastfeeding & $\begin{array}{l}\text { Early } \\
\text { Delayed }\end{array}$ & $\begin{array}{l}389(64.2) \\
217(35.8)\end{array}$ & - & - & - & $\begin{array}{l}166(67.2) \\
81(32.8)\end{array}$ & $\begin{array}{l}223(62.1) \\
136(37.9)\end{array}$ & 0.199 \\
\hline Gestational age at delivery & $\begin{array}{l}\text { Term }(\geq 37 \text { weeks }) \\
\text { Preterm ( }<37 \text { weeks) }\end{array}$ & $\begin{array}{c}566(93.4) \\
40(6.6)\end{array}$ & $\begin{array}{c}369(94.9) \\
20(5.1)\end{array}$ & $\begin{array}{c}197(90.8) \\
20(9.2)\end{array}$ & 0.053 & $\begin{array}{c}225(91.1) \\
22(8.9)\end{array}$ & $\begin{array}{c}34 I(95.0) \\
I 8(5.0)\end{array}$ & 0.058 \\
\hline Childbirth weight at delivery & $\begin{array}{l}\text { Normal or large birth } \\
\text { weight }(\geq 2500 \text { grams }) \\
\text { Low birth weight }(<2500 \\
\text { grams) }\end{array}$ & $\begin{array}{c}560(92.4) \\
46(7.6)\end{array}$ & $\begin{array}{c}372(95.6) \\
17(4.4)\end{array}$ & $\begin{array}{l}188(86.6) \\
29(13.4)\end{array}$ & $<0.001$ & $\begin{array}{c}223(90.3) \\
24(9.7)\end{array}$ & $\begin{array}{c}337(93.9) \\
22(6.1)\end{array}$ & 0.101 \\
\hline
\end{tabular}

Note: $*$ Missing data. 
Table 3 Multivariable Logistic Regression Analyses of Factors Associated with Delay Initiation of Breastfeeding Among Working Mothers with Children Under the Age of Two Years in Abu Dhabi, the United Arab Emirates

\begin{tabular}{|c|c|c|c|c|}
\hline \multirow{2}{*}{\multicolumn{2}{|c|}{ Variables }} & \multicolumn{3}{|c|}{ Delayed Initiation of Breastfeeding } \\
\hline & & $\begin{array}{l}\text { Crude Odds Ratio (OR)(95\% } \\
\text { Confidence Interval (Cl) }\end{array}$ & $\begin{array}{l}\text { Adjusted OR } \\
\qquad(95 \% \mathrm{Cl})\end{array}$ & P-value \\
\hline \multicolumn{2}{|l|}{ Maternal age, years } & $1.06(1.02,1.09)$ & $1.04(1.01,1.08)$ & 0.022 \\
\hline Nationality & $\begin{array}{l}\text { Non-Arab } \\
\text { Arab(Reference) }\end{array}$ & $2.40(1.68,3.42)$ & $2.24(1.53,3.27)$ & $<0.001$ \\
\hline Mode of delivery & $\begin{array}{l}\text { Caesarean delivery } \\
\text { Vaginal delivery(Reference) }\end{array}$ & $3.40(2.36,4.90)$ & $2.70(1.84,3.96)$ & $<0.001$ \\
\hline Rooming-in & $\begin{array}{l}\text { No } \\
\text { Yes(Reference) }\end{array}$ & $4.84(2.09,11.18)$ & $3.85(I .56,9.5 I)$ & 0.003 \\
\hline $\begin{array}{l}\text { Child birth weight at } \\
\text { delivery }\end{array}$ & $\begin{array}{l}\text { Low birth weight }(<2500 \text { grams) } \\
\text { Normal or large birth weight }(\geq 2500 \\
\text { grams) (reference) }\end{array}$ & $3.38(181,6.30)$ & $2.47(1.23,4.94)$ & 0.011 \\
\hline
\end{tabular}

Among the mothers who ceased breastfeeding $(n=242)$, 56 of their children were $\leq 6$ months old, 76 were $>6$ months -12 months, and the rest (110) were $>12$ months $<24$ months.

In multivariable logistic regression analysis, factors associated with cessation of breastfeeding among working mothers were being non-Arab nationality (AOR 1.59, 95\% CI 1.09, 2.31), and mother with high-income rating (AOR 2.79, 95\% CI 1.36, 5.75) (Table 4).

\section{Discussion}

The main findings of the current study were the estimation of the employment rate, prevalence, and factors associated with delayed initiation and cessation of breastfeeding among working mothers in Abu Dhabi, UAE.

The rate of employment was $37.6 \%$. Higher rates are expected as the women workforce has considerably increased in the UAE, and women are continuously achieving good performance in many positions. ${ }^{21}$

Despite the low rate of employment of mothers in different countries, working mothers face more challenges in comparison to non-working mothers regarding breastfeeding practices, such as insufficient breastfeeding support from society and healthcare providers, short maternity leave periods, difficulties associated with combining

Table 4 Multivariable Logistic Regression Analyses of Factors Associated Cessation of Breastfeeding Among Working Mothers with Children Under the Age of Two Years in Abu Dhabi, the United Arab Emirates

\begin{tabular}{|c|c|c|c|c|}
\hline \multicolumn{2}{|l|}{ Variables } & \multicolumn{3}{|c|}{ Cessation of Breastfeeding } \\
\hline & & $\begin{array}{c}\text { Crude Odds Ratio (OR)(95\%Confidence } \\
\text { Interval (Cl) }\end{array}$ & $\begin{array}{l}\text { Adjusted OR } \\
\quad(95 \% \mathrm{Cl})\end{array}$ & P-value \\
\hline Maternal education & $\begin{array}{l}\geq \text { Secondary level } \\
<\text { Secondary level(reference) }\end{array}$ & $2.5 \mathrm{I}(\mathrm{I} .08,5.84)$ & $2.11(0.89,4.98)$ & 0.088 \\
\hline Paternal education & $\begin{array}{l}\geq \text { Secondary level } \\
<\text { Secondary level(reference) }\end{array}$ & $3.30(1.13,9.62)$ & $2.82(0.96,8.34)$ & 0.060 \\
\hline Nationality & $\begin{array}{l}\text { Non-Arab } \\
\text { Arab(Reference) }\end{array}$ & $1.73(1.20,2.48)$ & $1.59(1.09,2.31)$ & 0.016 \\
\hline Pre-pregnancy BMI & $\begin{array}{l}\text { Normal BMI } \\
\text { Abnormal BMI (abnormal) }\end{array}$ & $1.49(1.07,2.09)$ & $1.38(0.98,1.95)$ & 0.067 \\
\hline Income rating & $\begin{array}{l}\geq \text { good } \\
<\text { good (reference) }\end{array}$ & $2.47(1.21,5.04)$ & $2.79(1.36,5.75)$ & 0.005 \\
\hline
\end{tabular}


breastfeeding and other maternal responsibilities, and emotional stress. $^{25-27}$

Among the 606 working mothers, 217 (35.8\%) delayed initiation of breastfeeding. This delay was found to be associated with various factors, namely, older maternal age, being of non-Arab nationality, caesarean section, non-rooming-in, and mothers with low birth weight children.

The rate of early initiation of breastfeeding (64.2\%) was similar to the previously reported rates in Nepal $(64 \%)^{28}$ and in India $(60 \%){ }^{29}$ However, it was higher than the reported rate in the neighboring country Saudi Arabia (34.3\%). ${ }^{30}$ The discrepancy of rates among countries may be attributed to the influence of other interactions of sociodemographics such as maternal education and income ${ }^{31}$ and obstetrical factors such as $\mathrm{CS}^{32}$

In this study, the association between the high rate of early initiation of breastfeeding among working mothers and low EBF was similarly reported in previous studies. ${ }^{12,13}$ For example, in Ghana, although $91 \%$ of the mothers early initiated breastfeeding, the EBF rate was low $(10.3 \%){ }^{12}$ This indicates that successful breastfeeding may require, besides early initiation of breastfeeding, other factors such as breastfeeding education, especially among working mothers.

The older age may contribute to delayed breastfeeding initiation through CS as there was an association between older age and CS. ${ }^{13}$ Other studies reported a similar association between older age and $\mathrm{CS}^{32,33}$

Interestingly, non-Arab mothers were more likely to delay initiation $\mathrm{AOR}=2.24(1.53,3.27)$ and to ceased breastfeeding $\mathrm{AOR}=1.59(1.09,2.31)$ in comparison to Arab ones. Breastfeeding practices variations, such as early initiation of breastfeeding among nationalities, were documented in previous studies, including the neighboring Kingdom of Saudi Arabia (KSA). ${ }^{34,35}$ Furthermore, the rate of CS was high among non-Arab mothers. ${ }^{36}$ This may negatively influence the early initiation ${ }^{36}$ and cessation of breastfeeding ${ }^{37}$ among non-Arab mothers. This indicates a need for more research to investigate such variations in breastfeeding practices among working mothers with different nationalities background, especially in a country like the UAE with a very diverse workforce. ${ }^{21}$

The results revealed that mothers' delivery via CS was almost three times at risk of delayed initiation of breastfeeding $A O R=2.70(1.84,3.96)$. Likewise to the results in the literature, it was well documented that CS is the main risk factor of delayed initiation of breastfeeding among working and non-working mothers, including the UAE country and others. ${ }^{38-42}$

In most of the studies, including systematic reviews, CS has been reported as a well-documented risk factor for not initiating breastfeeding within the first hour of life, both in the UAE and in many other countries. ${ }^{38-42}$ High CS rates have been correlated to many adverse effects, such as maternal mortality, neonatal mortality, infant mortality, LBW, and stillbirths. ${ }^{43}$ In the current study, the rate of CS was high (30.4\%). Therefore, any effort to reduce this high rate will ultimately improve breastfeeding practices, including early initiation and breastfeeding maintenance.

Non-rooming-in mothers were almost four times AOR $3.85(1.56,9.51)$ at risk of delayed initiation of breastfeeding. This is similar to the previous studies that have identified non-rooming-in among the most significant factors associated with non-breeding. ${ }^{44,45}$ According to the WHO, mothers with healthy full-term babies, including those born with CS, should stay in the same room together for the entire duration of 24 hours, except for periods of up to an hour for hospital procedures, starting from the time they come to their room after delivery, or as soon as they can respond to their babies in the case of CS. ${ }^{46}$ Several studies have found a strong association between roomingin and improved breastfeeding outcomes. ${ }^{4,48}$ Research shows the importance of rooming-in stems from the fact that following birth, whether, at home or at a hospital, mothers' and infants' physical and emotional needs for each other will continue. The more time the mother and newborn spend together, the better the breastfeeding practices. When together, mothers quickly learn their babies' needs and how best to care for, soothe, and comfort their newborns. Studies have revealed that mothers who roomin with their babies increase their milk production, breastfeed for longer periods, and are more likely to breastfeed exclusively compared to mothers who have limited contact with their infants (ie those with babies in the nursery at night). ${ }^{49-51}$ Researchers agree that rooming-in is positively associated with successful breastfeeding practices. A study in the UAE reported that mothers who kept their infants in the same room after delivery had a successful rate of breastfeeding 6 times higher than mothers who kept their infants in separate rooms. ${ }^{45}$

Working mothers are at greater risk of delivering LBW infants, especially those exposed to unfavorable working conditions. $^{52}$ LBW infants face many breastfeeding problems. The present study has showed that LBW infants are 
two and half times $\mathrm{AOR}=2.47(1.23,4.94)$ at risk of delayed initiation of breastfeeding compared to normal birth infants. This could be explained by the fact that LBW infants may need more care in the neonatal intensive care unit. ${ }^{53}$ In line with the current results, many studies reported that LBW is a risk factor for poor breastfeeding practices, including delayed initiation of breastfeeding. ${ }^{35,54}$ Thus, WHO recommends that LBW infants who can breastfeed should be put to the breast as soon as possible after birth and, when clinically stable, should be exclusively breastfed until six months of age. ${ }^{55}$

Breastfeeding among LBW infants can be improved through interventions targeting reducing the high rate of LBW and more support to the mothers with LBW infants.

Cessation of breastfeeding, especially at the age of 6 months and below, was found to be associated with poor infant and child outcomes. ${ }^{19,26}$ In the current study, among mothers who ceased breastfeeding 242/606 (40.8\%), 56 of them stopped breastfeeding at six months and below. A plethora of studies reported a return to work as one of the leading causes of early breastfeeding cessation. ${ }^{56}$ A recent report concluded that exclusive breastfeeding, late weaning, and maternal closeness, associated with advanced motor and vision maturation, independently influence autonomous behaviors in healthy children. ${ }^{57}$ Therefore, as a strategic plan, every effort should be directed to support all mothers to continue breastfeeding till two years and beyond. The measures that can assist the continuance of breastfeeding include having flexible work schedules and proximity of workplace to home, and creating a breastfeeding-friendly workplace. ${ }^{13,28,30}$

As the influence of family income on breastfeeding cessation has been equivocal, ${ }^{25,31,58}$ the current results go with high income associated with breastfeeding cessation. This association is scaling up even beyond the household level to country-level as in high-income countries, more than 1 in 5 never receive breastmilk. ${ }^{58}$

The study has several strengths, such as it was the first study on breastfeeding practices among working mothers that included a large sample size including both Emirati and non-Emirati mothers from both the health centers and the community in Abu Dhabi. On the other hand, there were some limitations. First, the recall bias as the study included children less than two years. Second, the nature of the study as the study was a cross-sectional one while a longitudinal study could provide more accurate information, ie, some children who were breastfeeding during the time of the data collection might stop breastfeeding later on. Third, unlike previous studies, ${ }^{30}$ it did not include data regarding the causes of breastfeeding cessation. Further studies that overcome the current limitations would be of great value to fully picture breastfeeding practices among working mothers. Therefore, in the future, more qualitative studies, including mothers from all emirates in the UAE, should be conducted to explore how returning to work affects mothers' decision to early discontinue any breastfeeding and early initiate formula feeding. Also, future work will be conducted comparing working mothers with non-working mothers regarding breastfeeding practices.

\section{Conclusions}

Policies to increase breastfeeding should address how both the time and circumstances of a mother's return to employment postpartum influence whether the mother decides to start breastfeeding. The study highlighted the need for urgent actions to improve the working mothers' conditions to promote optimal breastfeeding practices, including both early initiation and continuation of breastfeeding among all mothers in the UAE regardless of employment status. Health authorities should consider factors associated with delayed breastfeeding initiation and cessation of breastfeeding among working mothers in the UAE, such as older maternal age, caesarean section, non-rooming-in, and low birth weight children. Also, policies to improve EBF rates among professional working mothers should include maternity leave extension to enable mothers to continue breastfeeding.

\section{Acknowledgments}

The authors are grateful to the Abu Dhabi Health Services Company (SEHA) for granting access and approval to seven public ambulatory health care centers across the capital city of Abu Dhabi. We would like to express our gratitude to the mothers for their sincere cooperation and the provision of valuable information. Furthermore, we would like to thank the research assistants Amira Badr Eldin, Razan Abdelrahman, Nahed Yaghi, Nour Mohammed, Dhuha Abdulla Naser, Ayesha Rashed, and Jawaher Saeed, for their time and commitment.

\section{Author Contributions}

All authors made substantial contributions to conception and design, acquisition of data, or analysis and interpretation of data; took part in drafting the article or revising it critically for important intellectual content; agreed to submit to the current 
journal; gave final approval for the version to be published; and agreed to be accountable for all aspects of the work.

\section{Disclosure}

The authors declare no conflict of interests.

\section{References}

1. Saadeh M. A new global strategy for infant and young child feeding. Forum Nutr. 2003;56:236-238.

2. Organization, W.H. The World Health Report: 2005: Make Every Mother and Child Count. World Health Organization; 2005.

3. Kramer MS, Kakuma R. Optimal duration of exclusive breastfeeding. Cochrane Database Syst Rev. 2012;8.

4. Vaidya K, Sharma A, Dhungel S. Effect of early mother-baby close contact over the duration of exclusive breastfeeding. Nepal Med Coll J. 2005;7(2):138-140.

5. Godhia ML, Patel N. Colostrum-its composition, benefits as a nutraceutical-a review. Curr Res Nutr Food Sci J. 2013;1 (1):37-47. doi:10.12944/CRNFSJ.1.1.04

6. Critch JN, Society CP. Nutrition for healthy term infants, six to 24 months: an overview. Paediatr Child Health. 2014;19(10):547.

7. Bhutta ZA, Salam RA. Global nutrition epidemiology and trends. Ann Nutr Metab. 2012;61(Suppl. s1):19-27. doi:10.1159/000345167

8. Dieterich CM, Felice JP, O'Sullivan E, et al. Breastfeeding and health outcomes for the mother-infant dyad. Pediatr Clin North Am. 2013;60(1):31. doi:10.1016/j.pcl.2012.09.010

9. Taha Z. Trends of breastfeeding in the United Arab Emirates (UAE). Arab J Nutr Exerc. 2017;2(3):152-159. doi:10.18502/ajne.v2i3.1356

10. Wyatt S. Challenges of the working breastfeeding mother. Workplace solutions. AAOHN J. 2002;50(2):61-66. doi:10.1177/21650799020 5000204

11. Tadesse F, Alemayehu Y, Shine S, et al. Exclusive breastfeeding and maternal employment among mothers of infants from three to five months old in the Fafan zone, Somali regional state of Ethiopia: a comparative cross-sectional study. BMC Public Health. 2019;19 (1):1015. doi:10.1186/s12889-019-7345-5

12. Dun-Dery EJ, Laar AK. Exclusive breastfeeding among city-dwelling professional working mothers in Ghana. Int Breastfeed $J$. 2016;11 (1):23. doi:10.1186/s13006-016-0083-8

13. Chen J, Xin T, Gaoshan J, et al. The association between work related factors and breastfeeding practices among Chinese working mothers: a mixed-method approach. Int Breastfeed J. 2019;14(1):28 doi:10.1186/s13006-019-0223-z

14. Lauer EA, Armenti K, Henning M, et al. Identifying barriers and supports to breastfeeding in the workplace experienced by mothers in the new hampshire special supplemental nutrition program for women, infants, and children utilizing the total worker health framework. Int $J$ Environ Res Public Health. 2019;16(4):529. doi:10.3390/ijerph16040529

15. Murtagh L, Moulton AD. Working mothers, breastfeeding, and the law. Am J Public Health. 2011;101(2):217-223. doi:10.2105/AJPH. 2009.185280

16. Visness CM, Kennedy KI. Maternal employment and breast-feeding: findings from the 1988 national maternal and infant health survey. Am J Public Health. 1997;87(6):945-950. doi:10.2105/AJPH.87.6. 945

17. Hammer LD, Bryson S, Agras WS. Development of feeding practices during the first 5 years of life. Arch Pediatr Adolesc Med. 1999;153 (2):189-194. doi:10.1001/archpedi.153.2.189

18. Hawkins SS, Griffiths LJ, Dezateux C, et al. Maternal employment and breast-feeding initiation: findings from the Millennium Cohort Study. Paediatr Perinat Epidemiol. 2007;21(3):242-247. doi:10.11 11/j.1365-3016.2007.00812.x
19. Dagher RK, McGovern PM, Schold JD, et al. Determinants of breastfeeding initiation and cessation among employed mothers: a prospective cohort study. BMC Pregnancy Childbirth. 2016;16 (1):194. doi:10.1186/s12884-016-0965-1

20. Gebrekidan K, Hall H, Plummer V, Fooladi E. Exclusive breastfeeding continuation and associated factors among employed women in North Ethiopia: a Cross-sectional Study. 2020.

21. 24|7, F.E. UAE Ranks Among Most Developed Countries; 2014.

22. World Health Organization, United Nations Children's Fund. Global Nutrition Targets 2025: Breastfeeding Policy Brief. Geneva: WHO; 2014.

23. Gardner H, Green K, Gardner A. Infant feeding practices of Emirati women in the rapidly developing city of Abu Dhabi, United Arab Emirates. Int J Environ Res Public Health. 2015;12(9):10923-10940. doi:10.3390/ijerph120910923

24. Taha Z, Garemo M, Nanda J. Patterns of breastfeeding practices among infants and young children in Abu Dhabi, United Arab Emirates. Int Breastfeed J. 2018;13(1):48. doi:10.1186/s13006-0180192-7

25. Hunegnaw MT, Gelaye KA, Ali BM. Factors associated with the time to cessation of breastfeeding among mothers who have index children aged two to three years in Debre Markos, northwest Ethiopia: a retrospective follow up study. BMC Pediatr. 2018;18(1):77. doi:10.1186/s12887-018-1012-3

26. Al-Ruzaihan SA, Al-Ghanim AA, Bu-Haimed BM, et al. Effect of maternal occupation on breast feeding among females in Al-Hassa, southeastern region of KSA. J Taibah Univ Sci. 2017;12(3):235-240. doi:10.1016/j.jtumed.2016.08.013

27. Alebel A, Tesma C, Temesgen B, et al. Exclusive breastfeeding practice in Ethiopia and its association with antenatal care and institutional delivery: a systematic review and meta-analysis. Int Breastfeed J. 2018;13(1):31. doi:10.1186/s13006-018-0173-x

28. Sharma I, Khadka A. Assessing the level of knowledge and practice of breastfeeding among factory working mothers in Kathmandu, Nepal. $J$ Health Res. 2019;33(1):24-34. doi:10.1108/JHR-12-2018-0166

29. Ashoka A, Shwetha J, Mahesh T. A study of breastfeeding practices among working women in urban area of Davangere, Karnataka. Int J Contemp Pediatr. 2016;3:645-648.

30. Jabari M, Al-Hussein K, Al-Sayed M, et al. Breastfeeding practices among employed Saudi mothers. Med $J$ Cairo Univ. 2015;83:1159-1163.

31. Flacking R, Nyqvist KH, Ewald U. Effects of socioeconomic status on breastfeeding duration in mothers of preterm and term infants. Eur J Public Health. 2007;17(6):579-584. doi:10.1093/eurpub/ckm019

32. Elmugabil A, Rayis DA, Hassan AA, Ali AA, Adam I. Epidemiology of cesarean delivery in Kassala, Eastern Sudan: a community-based study 2014-2015. Sud J Med Sci. 2016;11(2):49-54.

33. Rydahl E, Declercq E, Juhl M, et al. Cesarean section on a riseDoes advanced maternal age explain the increase? A population register-based study. PLoS One. 2019;14(1):e0210655. doi:10.1371/ journal.pone. 0210655

34. McKinney CO, Hahn-Holbrook J, Chase-Lansdale PL, et al. Racial and ethnic differences in breastfeeding. Pediatrics. 2016;138(2): e20152388. doi:10.1542/peds.2015-2388

35. Alzaheb RA. Factors influencing exclusive breastfeeding in Tabuk, Saudi Arabia. Clin Med Insights. 2017;11:1179556517698136.

36. Taha Z, Ali Hassan A, Wikkeling-Scott L, et al. Prevalence and associated factors of caesarean section and its impact on early initiation of breastfeeding in Abu Dhabi, United Arab Emirates. Nutrients. 2019;11(11):2723. doi:10.3390/nu11112723

37. Hobbs AJ, Mannion CA, McDonald SW, et al. The impact of caesarean section on breastfeeding initiation, duration and difficulties in the first four months postpartum. BMC Pregnancy Childbirth. 2016;16 (1):90. doi:10.1186/s12884-016-0876-1

38. Alzaheb RA. A review of the factors associated with the timely initiation of breastfeeding and exclusive breastfeeding in the Middle East. Clin Med Insights Pediatr. 2017;11:1179556517748912. 
39. Radwan H. Patterns and determinants of breastfeeding and complementary feeding practices of Emirati mothers in the United Arab Emirates. BMC Public Health. 2013;13(1):171. doi:10.1186/14712458-13-171

40. Tongun JB, Sebit MB, Mukunya D, et al. Factors associated with delayed initiation of breastfeeding: a cross-sectional study in South Sudan. Int Breastfeed J. 2018;13(1):28. doi:10.1186/s13006-0180170-0

41. Tilahun G, Degu G, Azale T, et al. Prevalence and associated factors of timely initiation of breastfeeding among mothers at Debre Berhan town, Ethiopia: a cross-sectional study. Int Breastfeed J. 2016;11 (1):27. doi:10.1186/s13006-016-0086-5

42. Esteves TMB, Daumas RP, Oliveira MICD, et al. Factors associated to breastfeeding in the first hour of life: systematic review. Rev Saude Publica. 2014;48(4):697-708. doi:10.1590/S0034-8910.201404800 5278

43. Betran AP, Torloni MR, Zhang J, et al. What is the optimal rate of caesarean section at population level? A systematic review of ecologic studies. Reprod Health. 2015;12(1):57. doi:10.1186/s12978-0150043-6

44. Bandeira de Sá NN, Gubert MB, Santos WD, Santos LM. Factors related to health services determine breastfeeding within one hour of birth in the Federal District of Brazil, 2011. Rev Bras Epidemiol. 2016;19:509-524. doi:10.1590/1980-5497201600030004

45. Azzeh FS, Alazzeh A, Hijazi H, et al. Factors associated with not breastfeeding and delaying the early initiation of breastfeeding in Mecca Region, Saudi Arabia. Children. 2018;5(1):8. doi:10.3390/ children5010008

46. Organization, W.H. Baby-Friendly Hospital Initiative: Revised, Updated and Expanded for Integrated Care; 2009.

47. Elander G, Lindberg T. Short mother-infant separation during first week of life influences the duration of breastfeeding. Acta Paediatr. 1984;73(2):237-240. doi:10.1111/j.1651-2227.1984.tb09935.x

48. Verbowski V, Talukder Z, Hou K, et al. Effect of enhanced homestead food production and aquaculture on dietary intakes of women and children in rural Cambodia: a cluster randomized controlled trial. Matern Child Nutr. 2018;14(3):e12581. doi:10.1111/mcn.12581
49. Bystrova K, Widström A-M, Matthiesen A-S, et al. Early lactation performance in primiparous and multiparous women in relation to different maternity home practices. A randomised trial in St. Petersburg. Int Breastfeed J. 2007;2(1):9. doi:10.1186/17464358-2-9

50. Declercq ER, Sakala C, Corry MP, et al. Listening to mothers II: report of the second national US survey of women's childbearing experiences. J Perinat Educ. 2007;16(4):9-14. doi:10.1624/ $105812407 \mathrm{X} 244769$

51. Mikiel-Kostyra K, Mazur J, Wojdan-Godek E. Factors affecting exclusive breastfeeding in Poland: cross-sectional survey of population-based samples. Soz Praventivmed. 2005;50(1):52-59. doi:10.1007/s00038-004-3142-7

52. Mahmoodi Z, Karimlou M, Sajjadi H, et al. Association of maternal working condition with low birth weight: the social determinants of health approach. Ann Med Health Sci Res. 2015;5(6):385-391. doi:10.4103/2141-9248.177982

53. Gardner H, Green K, Gardner AS, et al. Observations on the health of infants at a time of rapid societal change: a longitudinal study from birth to fifteen months in Abu Dhabi. BMC Pediatr. 2018;18(1):32. doi:10.1186/s12887-018-1016-z

54. Khanal V, Scott J, Lee A, et al. Factors associated with early initiation of breastfeeding in Western Nepal. Int $J$ Environ Res Public Health. 2015;12(8):9562-9574. doi:10.3390/ijerph120809562

55. World Health Organization. Feeding of Low-Birth-Weight Infants in Low- and Middle-Income Countries; 2018.

56. Muda SM, Aung KT, Ibrahim AF, Ismail NA. Breast feeding issue: a Study on Factors Affecting Termination of breast feeding among working mothers. Int J Health Sci Res. 2016;6(9):257-263.

57. Villar J, Ochieng R, Staines-Urias E, et al. Late weaning and maternal closeness, associated with advanced motor and visual maturation, reinforce autonomy in healthy, 2-year-old children. Sci Rep. 2020;10 (1):1-27. doi:10.1038/s41598-020-61917-z

58. Unicef. Breastfeeding: A Mother's Gift, for Every Child. Unicef; 2018.

\section{Publish your work in this journal}

The International Journal of Women's Health is an international, peerreviewed open-access journal publishing original research, reports, editorials, reviews and commentaries on all aspects of women's healthcare including gynecology, obstetrics, and breast cancer. The manuscript management system is completely online and includes a very quick and fair peer-review system, which is all easy to use. Visit http://www.dovepress.com/testimonials.php to read real quotes from published authors. 